\title{
PERSISTENT LYMPHADENOPATHY IN LUPUS PATIENT ASSOCIATED WITH CASTLEMAN'S DISEASE: A CASE REPORT
}

\begin{abstract}
Raiza Cansian Tuão $0^{1, \star}$, Paula dos Santos Athayde ${ }^{1}$, Lídia Balarini da Silva ${ }^{1}$, Ketty Lysie Libardi Lira Machadoํㅜ, Bárbara Ferraço Dalmaso ${ }^{1}$, Gustavo Pinto de Oliveira Gomes ${ }^{1}$, Débora Marques Veghini ${ }^{1}$, Ruben Horst Duque ${ }^{1}$, Ana Paula Espíndula Gianordoli ${ }^{1}$,

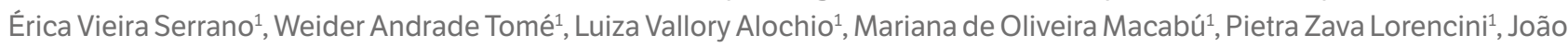
Peçanha Schuwartz ${ }^{1}$, Filipe Faé ${ }^{1}$, Maria Carmen Lopes Ferreira Silva Santos ${ }^{1}$, Valéria Valim ${ }^{1}$
\end{abstract}

1.Universidade Federal do Espírito Santo, Vitória (ES), Brazil.

*Corresponding author: raizatuao@hotmail.com

\section{BACKGROUND}

Systemic lupus erythematosus (SLE) is a chronic disease with a broad spectrum of clinical manifestations, such as lymphadenopathy, which may indicate disease activity and increased risk of lymphoproliferative disorders. Castleman's disease is a rare lymphoproliferative disorder characterized by heterogeneous manifestations that range from asymptomatic lymphadenopathy to severe systemic symptoms. We present a case of lymphadenopathy in a lupus patient with a histological diagnosis of Castleman's disease, a rare association.

\section{CASE REPORT}

This case concerns a 44-year-old female patient diagnosed with SLE since 2001, showing antinuclear antibody (ANA) 1/80 nuclear large/coarse speckled, complement consumption, discoid lesion, malar rash, arthritis and lymphopenia. Since diagnosis, she presented cervical lymphadenopathy, and two biopsies were performed in 2001 and 2009, with results of necrotizing lymphadenitis and simple reactive state with follicular hyperplasia, respectively. Patient took several medications during the course of the disease, such as thalidomide, methotrexate and dapsone, having good control of skin activity. In December 2019, she again presented with cervical lymph node enlargement, with worsening in March 2021. On examination, was observed lymphadenomegaly on posterior cervical on the right, measuring $2 \mathrm{~cm}$; occipital on the right, measuring $1 \mathrm{~cm}$; supraclavicular on the left, measuring $2.5 \mathrm{~cm}$; and preauricular on the left, measuring $1 \mathrm{~cm}$; all mobile and fibroelastic. A new biopsy was requested in May 2021, with histopathology demonstrating atypical lymphoid hyperplasia. Immunohistochemistry was compatible with hyaline vascular Castleman's disease (Figure 1). The hematology evaluation suggested conservative treatment, taking into consideration the locality of the lymph nodes and the patient being oligosymptomatic.

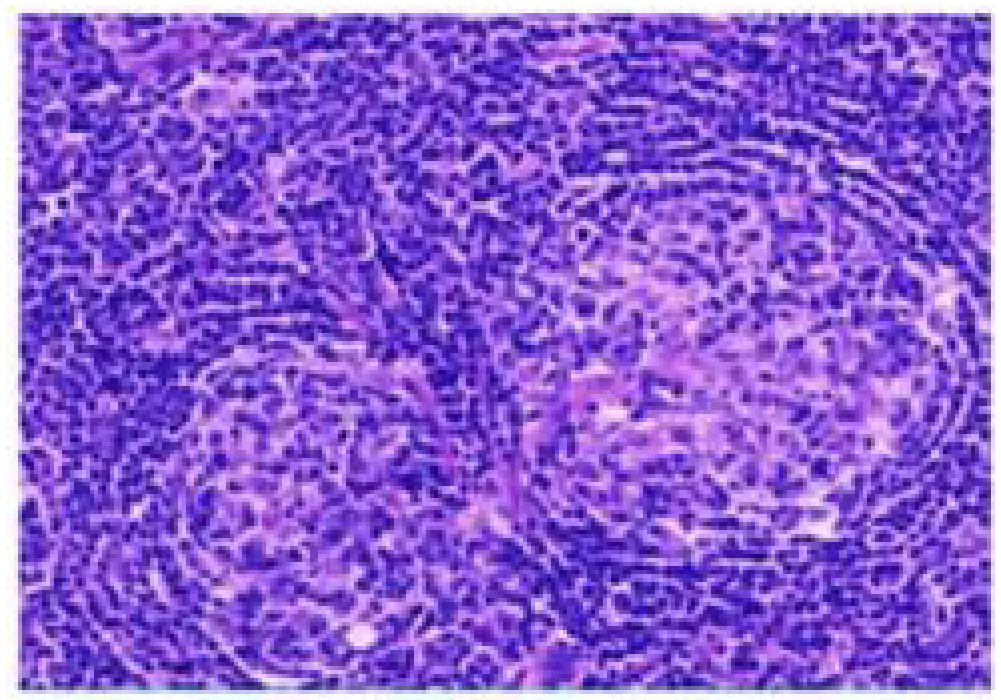

Figure 1. Immunohistochemistry showing immune lymph node with preserved general architecture, atrophy of germinal centers, prominence of the mantle zone, which presents itself concentrically arranged around the germinal centers (onion skin type), compatible with Castleman's disease.

Realização: 


\section{CONCLUSION}

Although lymphadenopathy is a finding of lupus, it may indicate underlying lymphoproliferative disorders. Thus, correlating clinical and histopathological findings becomes very important, since other diseases may be associated, such as Castleman's disease. If the lymphadenopathy is persistent, refractory to medications or even increases in volume, it is important to be aware and evaluate a new biopsy, in addition to monitoring clinical and laboratory markers of lymphoproliferative diseases.

\section{KEYWORDS}

Castleman disease, Lupus erythematosus systemic, Lymphadenopathy, Lymphoproliferative disorders. 